Int. J. Electrochem. Sci., 11 (2016) 3931 - 3937

\title{
Electrochemical Analysis of 2-chlorophenol Using a Multi- Walled Carbon Nanotube-Ionic Liquid Composite Modified Electrode
}

Jianxiang Jin, Benzhi Liu*, Bairen, Yang, Yonghang Gan, Chengbin Bao

School of Environmental Science and Engineering, Yancheng Institute of Technology, Yancheng, Jiangsu Province, China

*E-mail: lbzycit@163.com

doi: $10.20964 / 1103101$

Received: 23 January 2016 / Accepted: 19 February 2016 / Published: 1 April 2016

A multi-walled carbon nanotube-ionic liquid composite modified glassy carbon electrode was fabricated. The modified electrode showed highly catalytic ability towards the oxidation of 2chlorophenol. Square wave voltammetry was used for the determination of 2-chlorophenol. The oxidation peak currents were linearly with the concentrations of 2-chlorophenol in the range of 0.5 to $12.0 \mu \mathrm{M}$, with a detection limit of $0.1 \mu \mathrm{M}$. The proposed method was successfully applied for the determination of 2-chlorophenol in water samples with satisfactory recoveries.

Keywords: 2-chlorophenol; Modified electrode; Multi-walled carbon nanotube; Ionic liquid

\section{FULL TEXT}

(C) 2016 The Authors. Published by ESG (www.electrochemsci.org). This article is an open access article distributed under the terms and conditions of the Creative Commons Attribution license (http://creativecommons.org/licenses/by/4.0/). 